\title{
Impacts of Biomass Burning in the Atmosphere of the Southeastern Region of Brazil Using Remote Sensing Systems
}

\author{
F. J. S. Lopes, G. L. Mariano, E. Landulfo and E. V. C. Mariano \\ Additional information is available at the end of the chapter
}

http://dx.doi.org/10.5772/50406

\section{Introduction}

Usually, both for the scientific community and to the general public, there is a tendency to associate air pollution with large urban centers (mainly coming from motor vehicles or factory chimneys). However, large areas, especially tropical regions, live with another source of pollution: the biomass burning. According to the Intergovernmental Panel on Climate Change (IPCC) report, biomass burning is the major source of air pollution and is considered an important environmental problem with several impacts on local, regional and global levels [1]. Biomass burning includes burning of forests, grasslands, and croplands. Large quantities of gases and materials, besides trace elements, are emitted into the atmosphere by this action. This can affect both the regional and global climate through the interaction with solar radiation and the chemical and physical processes in the atmosphere. A large amount of these burning points occurred in the southern part of the Amazon basin during the dry season and the product of these emissions can be transported to some cities in the southeast of the country, a highly polluted region, and with cities with serious air pollution problems at the urban environment. Moreover, with the growing demand for biofuels in Brazil, the cultivation of sugarcane has been expanding considerably in southeastern Brazil, being a strong contribution to poor air quality in the region due to the burning of that culture, aiming to facilitate its harvest.

A very useful tool in studies of the effects of burning in the atmosphere is the Lidar (Light Detection and Ranging) technique, which gives vertical profiles of aerosols and allows the monitoring of the temporal evolution of the atmospheric structure, as well as to obtain values of backscattering coefficient. This technique is characterized by high spatial and temporal resolution, allowing the measurement of small concentrations of different gases (mainly water vapor), aerosols and local meteorological parameters such as wind direction 
and temperature, depending, however, on the type of Lidar system and the wavelength used.

A Lidar system operates on the same physical principle of Radar, but using a laser beam as emission source; the detection components are composed by a telescope and an optical analyzer system. In the case of Lidar, a light pulse is directed into the atmosphere. The light beam interacts with the atmospheric compounds and is scattered in all directions by particles and molecules. A portion of the light is absorbed and other portion is scattered back towards the Lidar system. The backscatter light is collected by a telescope and focused upon a photo detector capable to measure the signal intensity as function of the distance from the system.

Lidar systems, both aboard of satellites and ground-based, have been used in synergy with sunphotometer systems to detect and track the transport of aerosol from the MidWestern portion of the Brazilian territory to the Southeastern region, mainly the São Paulo city, where a ground-based elastic backscatter Lidar system is installed [2]. Here, some results obtained using a methodology developed to detect biomass burning aerosol loaded in the atmosphere at specific locations of the Brazilian territory will be presented, mainly in the Midwestern and Northern portion, considered to be one of the biggest producers of biomass burning in South America due to the vast quantities of forest, pasture and plantations, and track the transport trajectories of the aerosol plumes into the areas located at the Southeastern portion of Brazil, in the city of São Paulo, where it is possible to identify such plumes using the AERONET sunphotometer and the elastic backscatter Lidar system. Initially, Ångström Exponent (AE) and Aerosol Optical Depth (AOD) values retrieved from the AERONET sunphotometer network and the MODIS satellite, combined with AOD and Lidar ratio (LR) products from the CALIOP measurements are used in order to identify biomass burning aerosols loaded in the atmosphere in the MidWestern and Northern portion of the Brazilian territory. Attenuated backscatter profile images and aerosol optical properties values from CALIOP are used to monitor and track such aerosol plumes to the Southeastern region. If the transportation of biomass burning to São Paulo city is confirmed using the HYSPLIT (Hybrid Single Particle Lagrangian Integrated Trajectory Model) backtrajectories, the backscatter Lidar and the sunphotometer data are used to analyze the presence of those plumes at the São Paulo atmosphere. Such results can be a strong indication that the city of São Paulo, one of the most polluted cities in the world, is affected not only by the presence of aerosol from local sources but also by aerosols produced in remote sources.

\section{Instrumentation}

This study has the aim of analyzing the biomass burning aerosol optical properties using data from the CALIOP sensor installed on board the satellite CALIPSO and MODIS sensor aboard the TERRA and AQUA satellite. In addition, ground-based data measurements such as an elastic backscatter Lidar system and the AERONET sun photometer data will be used. In this section some details of each instrument will be presented. 


\subsection{Moderate Resolution Imaging Spectroradiometer (MODIS) Sensor}

Through the EOS (Earth Observing System) program, initiated in 1980 with the main objective to allow continuous observations for a period of at least 15 years of global changes, various sensors have been launched, and among them the MODIS in 1999 (Moderate Resolution Imaging Spectroradiometer) is highlighted.

The MODIS sensor is on board the polar orbiting satellites TERRA and AQUA launched in 1999 and 2002, respectively. The sensor was the first designed to obtain global observations of aerosols with moderate resolution (between $250 \mathrm{~m}$ and $1000 \mathrm{~m}$ depending on the wavelength used).

The AQUA satellite is part of the so-called A-Train constellation [3], which also contains the Aura satellite (launched in 2004) to study the atmospheric chemistry and dynamics with emphasis on the sensor for ozone monitoring OMI - Ozone Monitoring Instrument, PARASOL (2004) to study the water and carbon cycle, CALIPSO (2006) to study the profile of aerosol and clouds and CloudSat (2006) to study the clouds.

MODIS has 36 spectral bands between 0.4 and $14.5 \mu \mathrm{m}$, allowing the generation of several products related to aerosol, such as aerosol optical depth over the ocean and land with a resolution of 10x10 km (at nadir), and the size and type distribution over oceans and type of aerosol over the continent. General and operational characteristics of the sensor can be found in Barnes et al. (1998) [4].

The MODIS aerosol data analyzed consist of the aerosol product level 3, MOD08. This level of data is generated daily for the entire globe offering several properties related to aerosols such as optical depth over ocean/continent and Ångström Exponent over the continent. The spatial resolution of the data is $1.0^{\circ}$ for level 3 . In this chapter, data from the AOD MODIS sensor (AQUA satellite) between 2003 and 2010 were used.

Any given set of data, ordered from the lowest to the highest value, have a central value which is called a median. Likewise, it is possible to think of the values dividing the set of data in four equal parts, that is, the quartiles, Q1, Q2 and Q3, with Q2 being equal to the median. The values dividing the set in 10 equal parts are the deciles, and the values which divide the set in 100 equal parts are the percentiles. A percentile is the value of a data set below which a certain amount of the observations are. For instance, the 90th percentile represents the number below which $90 \%$ of the data is found. The 50th percentile is equivalent to the median [5].

The AOD is a dimensionless coefficient, indicating the amount and efficiency of solar radiation extinction by optically active material for a given wavelength. The optical depth may be defined as an attenuation coefficient of a beam of light which undergoes scattering or absorption during its passage through any given element [6].

Higher values of optical depth lead to lower values for the optical transmittance of the air column, with the intensity of solar radiation on the surface also being smaller. Consequently, the temporal and spatial evolution of this radiation depends on the 
atmospheric optical depth, which will depend on local factors, since these cause variations in how the solar radiation in the electromagnetic spectrum and the direction of propagation is distributed.

The AOD can be divided into some components, due to Rayleigh and Mie scattering, as well as the absorption by atmospheric particles. Therefore, the optical depth is a measure of transparency, being defined as the fraction of radiation (or light) that is scattered or absorbed in a path. An easy example is that of a fog. The fog between an observer and an object immediately in front of him has an optical depth tending to zero. If the object is moving away from the observer's, the optical depth will increase until it reaches a large value where the object is no longer visible.

The optical depth indicates the amount of absorbing and scattering optically active material found in the path of a beam of radiation. It is defined as the integral over the optical path of the product of the total quantity of molecules present in the medium and the cross section of extinction for each wavelength. The optical depth is expressed by:

$$
\tau_{\lambda}=\int \sigma_{\lambda} N(x) d x
$$

Where $\sigma_{\lambda}$ is the extinction cross section, $\mathrm{dx}$ the path of integration and $\mathrm{N}(\mathrm{x})$ the volume number density of optically active atoms or molecules [particles $\mathrm{cm}^{-2}$ ] [6]. It expresses the amount of light removed from a beam by scattering or absorption during its path in any means. Being $I_{0}$ the intensity of the radiation source and I the intensity observed after a certain path, the optical depth may be defined by the following equation:

$$
\frac{I}{I_{0}}=e^{-\tau}
$$

In the atmospheric sciences, the atmospheric optical depth is commonly referred as the vertical path from the surface of the earth or the altitude of the observer into space. Since it regards the vertical path, the optical depth of a sloping path is $\tau^{\prime}=\mu \tau$, which is called the air mass factor, which to that atmosphere is usually defined as $\mu=1 / \cos \Theta$ where $\Theta$ is a zenith angle corresponding to a certain path. Thus:

$$
\frac{I}{I_{0}}=e^{-\mu \tau}
$$

\subsection{CALIPSO satellite}

Ground-based systems are very useful for monitoring local and regional aerosol properties in the atmosphere, playing an important role in the estimation of the aerosol influence on the radiation budget. However, in order to cover the cloud and aerosol vertical distribution in a global range, NASA and CNES agencies has launched a satellite with a Lidar system as a main operational instrument on board [7]. The CALIPSO satellite was launched in April 2006, and since then is part of the NASA's A-Train satellite constellation as mentioned before. CALIPSO is flying in a $705 \mathrm{~km}$ sun-synchronous polar orbit with an equator-crossing time of about 13:30 in local time, covering the whole globe in a repeat cycle of 16 days [8]. The CALIPSO payload consists of three co-aligned nadir-pointing instruments designed to 
operate autonomously and continuously. Two of them are passive sensors and can provide a view of the atmosphere surrounding the Lidar curtain, namely, a wide field camera with a spatial resolution of $125 \mathrm{~m}$ for pixels and a three-channel infrared imaging radiometer instrument at each of the two wavelengths [9]. The lasers are Q-Switched to provide a pulse length of about $20 \mathrm{~ns}$. The receiver subsystems measure the attenuated backscattering signal intensity at $1064 \mathrm{~nm}$ and the two orthogonal polarization components at $532 \mathrm{~nm}$. From the backscattering signal measured by the receiver system, the CALIOP data products are assembled and separated in two categories: Level 1 and 2 products. Level 1 products are composed of calibrated and geolocated profiles of the attenuated backscatter returned signal, and are separated in three types, the total attenuated backscatter profile at $1064 \mathrm{~nm}$, total attenuated backscatter profile (the sum of parallel and perpendicular signals) and the perpendicular backscatter signal, both at $532 \mathrm{~nm}[8,10]$. The level 2 products are derived from level 1 products and are classified in three types: layer products, profile products and vertical feature mask (VFM). Layer products provide the optical properties of aerosol and clouds integrated or averaged in the layers detected in the atmosphere. The profile products provide retrieved backscatter and extinction profiles within the detected layers. The VFM provide information of the cloud and aerosol location, and also their types. The level 2 data of aerosol layers provide information about values of the AOD, LR, and information from the heights of top and bottom of the layers detected by the CALIOP sensor.

\subsection{AERONET sunphotometer}

AERONET is a global network of optical monitoring of atmospheric aerosols, maintained by NASA and expanded throughout various research institutions around the world. This network has more than 200 measuring points, 22 in South America. The sunphotometer system from the AERONET network is a remote sensing instrument very useful not only to work in synergy with Lidar but also to retrieve several optical properties from aerosol loaded in the atmosphere.

The CIMEL 318A spectral radiometer is a solar-powered weather-hardy robotically pointed Sun and sky instrument. This instrument is installed on the roof of the Physics Department at the University of São Paulo (USP). The CIMEL photometer performs measurements of the AOD at several wavelengths in the visible and the near-infrared spectral region to enable the assessment also of the Ångström Exponent [11]. The principle of operation of this system is to acquire aureole and sky radiances observations using a great number of scattering angles from the Sun, through a constant aerosol profile to retrieve the aerosol size distribution, the phase function and the AOD. For this study, the channels used are centered at $340,440,500,670,870,940$ and $1020 \mathrm{~nm}$, with a $1.2 \mu \mathrm{m}$ full FOV (field of view) angle. The measurements are taken pointed directly to the Sun (four sequences) or to the sky (five sequences) in nine different pre-programmed sequences [11]. The inversion of the solar radiances measured by the CIMEL sunphotometer to retrieve the aerosol optical depth values is based on the Beer-Bouguer-Lambert equation, assuming that the contribution of multiple scattering within the small FOV of the sunphotometer is negligible. The aerosol optical depth at $532 \mathrm{~nm}$ was determined by the relation: 


$$
\frac{\tau_{532}^{a e r}}{\tau_{500}^{a e r}}=\left(\frac{532}{500}\right)^{-a}
$$

Where the Ångström Exponent [12] was derived from the measured optical depth in the blue and red channels (440 $\mathrm{nm}$ and $670 \mathrm{~nm}$ ):

$$
a=-\frac{\log \left(\frac{\tau_{440}^{a e r}}{\tau_{670}^{a+r}}\right)}{\log \left(\frac{440}{670}\right)}
$$

The AE is also an indirect mean to retrieve the particle size distribution [13] and its possible composition [14, 15]. Concerning the uncertainty, the major source of error would be in the calibration procedure, which is proportional to the associated uncertainty of the AOD at a given wavelength [16].

\subsection{Elastic backscatter Lidar system (MSP-Lidar)}

A ground-based elastic backscatter Lidar system is in operation since 2001 in the Environmental Laser Applications Laboratory at the Centre for Laser and Applications (CLA) at the Nuclear Energy Research Institute (IPEN). The MASP and instrument locations in this area are depicted in Figure 1 (point L).

The Lidar technique is based on the emission of a collimated laser beam through the atmosphere and on the detection of the backscattered laser light by the suspended atmospheric aerosols and molecules. A backscattering Lidar can thus provide information on the Planetary Boundary Layer (PBL) mixed depth, entrainment zones and convective cell structure, aerosol distribution, clear air layering, cloud-top altitudes, cloud statistics, atmospheric transport processes and other inferences of air motion [17-20]. The Lidar system is a single-wavelength backscatter system pointing vertically to the zenith and operating in the coaxial mode. The light source is based on a commercial Nd:YAG laser (Brilliant by Quantel SA) operating at the second harmonic frequency (SHF), namely at 532 $\mathrm{nm}$, with a fixed repetition rate of $20 \mathrm{~Hz}$. The average emitted power can be selected up to values as high as $3.3 \mathrm{~W}$. The emitted laser pulses have a divergence of less than $0.5 \mathrm{mrad}$. A $30 \mathrm{~cm}$ diameter telescope (focal length $\mathrm{f}=1.5 \mathrm{~m}$ ) is used to collect the backscattered laser light. The telescope's FOV is variable (1-2 mrad) by using a small diaphragm. Lidar is currently used with a fixed FOV of the order of $1 \mathrm{mrad}$, which according to geometrical calculations [21] permits a full overlap between the telescope FOV and the laser beam at heights around $300 \mathrm{~m}$ above the Lidar system. This FOV value, in accordance with the detection electronics, permits the probing of the atmosphere up to the free troposphere (12$15 \mathrm{~km}$ asl). The backscattered laser radiation is then sent to a photomultiplier tube (PMT) coupled to a narrowband ( $1 \mathrm{~nm}$ full width at half maximum - FWHM) interference filter to assure the reduction of the solar background during daytime operation and to improve the signal-to-noise ratio (SNR) at altitudes greater than $3 \mathrm{~km}$. The PMT output signal is recorded by a Transient Recorder in both analog and photon counting modes. Data are averaged between 2 and $5 \mathrm{~min}$ and then summed up over a period of about $1 \mathrm{~h}$, with a typical spatial resolution of $15 \mathrm{~m}$, which corresponds to a $100 \mathrm{~ns}$ temporal resolution. 




Figure 1. Metropolitan Area of São Paulo (MASP) map with the sampling locations indicated: (1) São Paulo University Campus (USP), site of the Lidar and AERONET sunphotometer, in the point L.

In the present stage, the inversion of the Lidar profile is based on the solution of the basic Lidar equation taking into account the atmospheric solar background radiation correction [22]. The Lidar equation is presented according to equation (6), where $P(\lambda, z)$ is the Lidar signal received from a distance $z$ at the wavelength $\lambda, P_{0}$ is the emitted laser power, $\xi$ is all Lidar system parameters, $\beta_{\mathrm{m}}(\lambda, z)$ and $\beta_{\mathrm{aer}}(\lambda, z)$ are the atmospheric volume backscatter coefficients for the molecular and aerosol contribution, respectively; and $\alpha_{\text {aer }}(\lambda, z)$ is the volume extinction coefficient at range $\mathrm{z}$.

$$
P(\lambda, z)=P_{o} \xi\left[\frac{\beta_{m}(\lambda, z)+\beta_{a e r}(\lambda, z)}{z^{2}}\right] \times \exp \left[-2 \int_{0}^{z} \alpha\left(\lambda, z^{\prime}\right) d z^{\prime}\right]
$$

The retrieval of the aerosol optical properties is based on the measurements of the aerosol backscatter coefficient $\beta_{\text {aer }}$ at $532 \mathrm{~nm}$, up to an altitude of 5 to $8 \mathrm{~km}$. The determination of the vertical profile of the aerosol backscatter and extinction coefficients relies on the Lidar inversion technique following a modified Klett's algorithm [23, 24] under the assumption of the single scattering approximation. One has, however, to bear in mind that this inversion technique is an ill-posed problem in the mathematical sense, leading to errors as large as $30 \%$ when applied [22]. To make the Lidar equation solvable it is necessary to establish a relation between $\alpha(\lambda, z)$ and $\beta(\lambda, z)$. This is achieved assuming the backscatter-to-extinction ratio (LR) as:

$$
L R=\frac{\alpha_{a e r}(\lambda, z)}{\beta_{a e r}(\lambda, z)}
$$


However, it is known that the LR depends on several physical-chemical parameters inherent to the aerosols being inspected, such as the aerosol refractive index, size and shape distribution of the aerosol particles [25]. To derive the appropriate "correct" values of the vertical profile of aerosol backscatter coefficient in the lower troposphere an iterative inversion approach was used (by "tuning" the LR values), based on the intercomparison of the AOD values derived by the Lidar and a collocated AERONET sunphotometer [26], assuming the absence of stratospheric aerosols and that the PBL is homogeneously mixed between ground and the altitude of $300 \mathrm{~m}$, where the Lidar overlap factor is close to 1 . Once the correct values of the vertical profile of the aerosol backscatter coefficient were derived (when the difference between the AODs derived by sunphotometer and Lidar was less than $10 \%$ ), the Klett's inversion technique was reapplied, using the appropriate LR values, to retrieve the final values of the vertical profiles of the backscatter and extinction coefficient at $532 \mathrm{~nm}$. The vertical profiles of pressure and temperature measured by radiosoundings launched twice a day, at 12 UTC and 00 UTC in a distance about $10 \mathrm{~km}$ from the place where the MSP-Lidar system is located, are used in order to obtain the molecular contribution based in the Bucholtz's approach [27].

\section{Analysis of the active fires in the state of São Paulo}

The fire detection method employed by INPE (National Institute for Space Research) is a digital non supervised clustering algorithm which selects pixels as burning if the AVHRR radiometric temperature exceeds $46^{\circ} \mathrm{C}$ [28], using the images of several satellites, which operate in the band between 3.7 and $4.1 \mu \mathrm{m}$, selecting the pixels (resolution elements) with higher temperature. Data from the morning overpass are used to identify fire pixels. Fire counts identified by INPE are provided in a weekly base in grid format. They consist of a 7day sum at 0.5 -degree increments from $17^{\circ} \mathrm{N}$ to $40^{\circ} \mathrm{S}$ and $85^{\circ} \mathrm{W}$ to $34.5^{\circ} \mathrm{W}$ [29]. Data of active fires obtained through the NOAA-12 satellite were used, for the period between January, 1999 and July, 2007 at the studied region (pixels located over the state of São Paulo).

Through the spatial distribution of fires (Figure 2) obtained by the NOAA-12 satellite, it is possible to notice that the regions with the highest number of outbreaks of fires during the selected period coincides with sugarcane crops, especially during the winter and spring, periods with the largest number of outbreaks. The central-northern, central, central-eastern and central-western regions of the São Paulo State are highlighted as the areas where there is a high rate of outbreaks due to the presence of the sugarcane culture.

The results of Figure 2 and Table 1 indicate that the winter was the season with the highest number of fire outbreaks during the period, when approximately 15,000 outbreaks were recorded, followed closely by spring with approximately 12,000 outbreaks, while in summer only 2000 spots were registered. During the harvest period, which occurs from May to November, the plantation areas are burnt a few hours before the manual cutting, and this period coincides with the dry season in Southeastern Brazil. From December to April the wet pattern prevails and there are only few activities for burning around the 
state of São Paulo. The number of fire outbreaks tends to increase from the month of March, achieving its maximum in the trimester July-August-September. The peak of the burning season (August) coincides with the least amount of precipitation in the region, while the reverse is also found, burning minimum in the months with maximum precipitation (December and January).

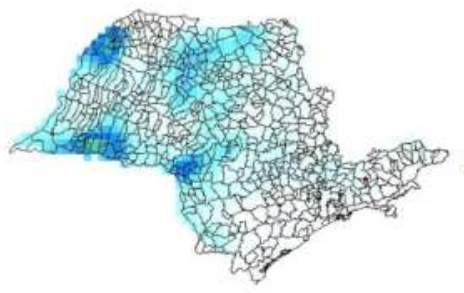

(a)

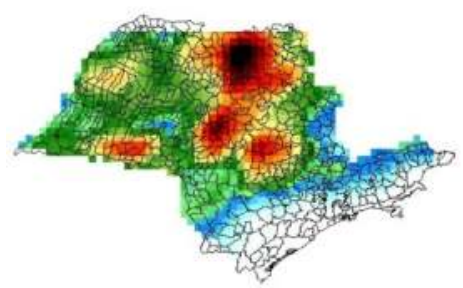

(c)

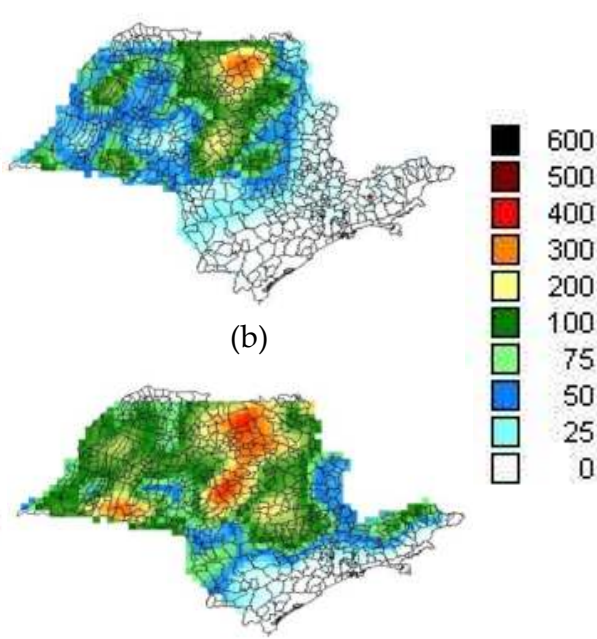

(d)

Figure 2. Outbreaks of fire during the period from January, 1999 to July, 2007: (a) summer; (b) autumn; (c) winter and (d) spring.

The great quantity of active fires during the dry season, combined with low humidity in the region, can cause several health problems in the people living near the plantations and burnings of sugarcane. The association between internal and external exposure to the biomass smoke and its effects on health has been reported in some areas of Asia and India $[30,31]$. Carbon deposition in the lungs occurred consistently in patients exposed to biomass burning [32]. Unlike most regions where external biomass burning is sporadic, the biomass burning in the region of São Paulo is a common and scheduled activity, due to the areas with sugarcane crops.

The seasonal and interannual variation of the active fires in the State of São Paulo can be analyzed in Table 1. Through this table it can be noticed that the highest value of active fires occurred in 1999 followed by a decrease until 2001. From this year on, a slightly constant tendency of decrease in numbers of forest fires was noticed, except for the two last measured years (2005 and 2006). It is important to highlight that the measurements and monitoring in 2007 only goes until July, before the burning maximum period - August, September and October (as seen on Figure 2), probably due to technical problems with the satellite acquisitions. Besides the annual active total fires, the seasonal variation of the 
number of fires for each year can also be observed in the Table 1, where it can be clearly seen that the maximum active fires seasons are winter and spring, followed by autumn and summer in almost every analyzed year, except for the years of 2000 and 2004, where the total active fires detected were greater in spring and summer than in winter and autumn, respectively. For the year of 2004, it was observed that the rain rates for these two periods were normal according to the climatology, without an obvious reason for that variation. It can also be seen the difference between the number of fires during the maximum fires season (winter) and the minimum (summer), reaching a value 3 times higher at some periods.

\begin{tabular}{|c|c|c|c|c|c|}
\hline Year/ Season & Summer & Autumn & Winter & Spring & Total \\
\hline $\mathbf{1 9 9 9}$ & 57 & 924 & 2633 & 2401 & 6090 \\
\hline $\mathbf{2 0 0 0}$ & 598 & 451 & 2202 & 1288 & 4489 \\
\hline $\mathbf{2 0 0 1}$ & 78 & 277 & 1658 & 1026 & 3091 \\
\hline $\mathbf{2 0 0 2}$ & 120 & 670 & 1657 & 1416 & 3829 \\
\hline $\mathbf{2 0 0 3}$ & 97 & 519 & 1759 & 1065 & 3420 \\
\hline $\mathbf{2 0 0 4}$ & 74 & 387 & 1118 & 1484 & 3171 \\
\hline $\mathbf{2 0 0 5}$ & 215 & 680 & 1912 & 1498 & 4174 \\
\hline $\mathbf{2 0 0 6}$ & 53 & 933 & 1889 & 1490 & 4398 \\
\hline $\mathbf{2 0 0 7}$ & 108 & 602 & 306 & - & 983 \\
\hline Total & $\mathbf{9 9 3}$ & $\mathbf{5 4 4 3}$ & $\mathbf{1 5 1 3 4}$ & $\mathbf{1 1 6 6 8}$ & $\mathbf{3 3 6 4 5}$ \\
\hline
\end{tabular}

Table 1. Active fires measured by the NOAA-12 satellite for the State of São Paulo - Brazil

\section{MODIS aerosol optical depth}

Figure 3 shows the maximum values of AOD for the southeastern region of Brazil from 2003-2010 (latitude between $14^{\circ} \mathrm{S}$ and $25^{\circ} \mathrm{S}$ and longitude between $54.1^{\circ} \mathrm{W}$ and $38.1^{\circ} \mathrm{W}$ ). This region is known for having main urban centers, especially the metropolitan area of São Paulo and Rio de Janeiro, with large amounts of industries. In addition, the city of Cubatão is located at this region (50 km from MASP), in the state of São Paulo, known in the 1980s and 1990s as one of the most polluted cities in the world [33].

Despite the known major sources of pollution in the southeastern region of Brazil, it is possible to notice high maximum AOD values only during spring and winter. Except for these periods, and for one day in 2003 and other in 2010, both at summer, the maximum AOD over the Southeastern region was always below 1.0. The average of the maximum AOD between 2003 and 2010 was $0.492 \pm 0.505$, indicating the high variability of the maximum AOD over the region.

The $95^{\text {th }}$ percentile calculated using data on maximum daily AOD for the southeastern region of Brazil was 1.143. This means that 95\% of the daily data (MOD08) from the MODIS sensor (from a total of 2921 measurements spanning from 2003 to 2010) have lower values than 1.143. At first, this value can be considered low, but aspects of the sensor used must be taken into account, such as a spatial resolution of $1 \mathrm{~km}$ and that the 
maximum concentration of aerosols tends to be found near the surface, hindering the use of remote sensing for this task.
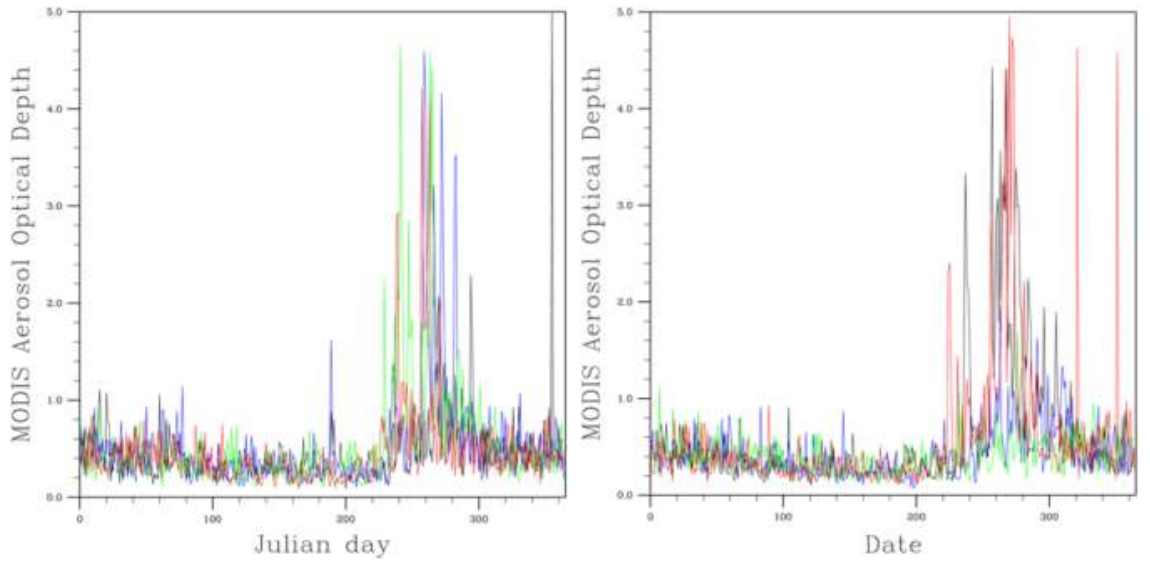

Figure 3. MODIS Maximum Aerosol Optical Depth over southeast of Brazil (a) 2003-2006 and (b) 20072010. Years: (a) 2003 (orange); 2004 (blue); 2005 (green); 2006 (red) and (b) 2007 (orange); 2008 (blue); 2009 (green); 2010 (red)

Both the Amazon and Midwestern Brazil are great sources of aerosols into the atmosphere, and the maximum daily value of AOD found on the Southeastern region can be compared to these areas. In all of these regions the largest occurrences of elevated AOD are during the winter and spring in the Southern Hemisphere. The occurrence of higher AOD levels during this period for the Northern and Central region is basically due to the highest amount of biomass burning in the region (dry season). In Brazil, biomass burning in the Amazon region occurs with greater intensity during the dry season (July - October) and primarily affects the ecosystems of forest, pasture and Cerrado [34]. The small amount of precipitation and the increased atmospheric stability at this period contributes to the persistence of aerosols in the atmosphere, as well as a higher transport of biomass burning aerosols from the Amazon region (Section 6).

Analyzing the 146 days with maximum AOD higher than the 95 between $2003-2010$ it is observed that approximately $82 \%$ of the cases occurred during the spring in the Southeastern hemisphere (Figure 4). When considering the period corresponding for spring and winter, the same has 144 days with values above the 95th percentile ( $99 \%$ approximately). The emissions from these fires have significant impacts on the concentration of gases and aerosols. The results presented here emphasize the importance of monitoring the aerosols for the period between June and October. The values recorded during summer and fall may be related, among other reasons, with burning events in the Southeastern region and transport of biomass burning aerosols from distant regions, such as the Amazon and MidWestern region of Brazil regions, Bolivia, the Northern portion of Argentina and the North region of South America. Another possible explanation for the values found are the urban aerosols emitted into the studied area. 


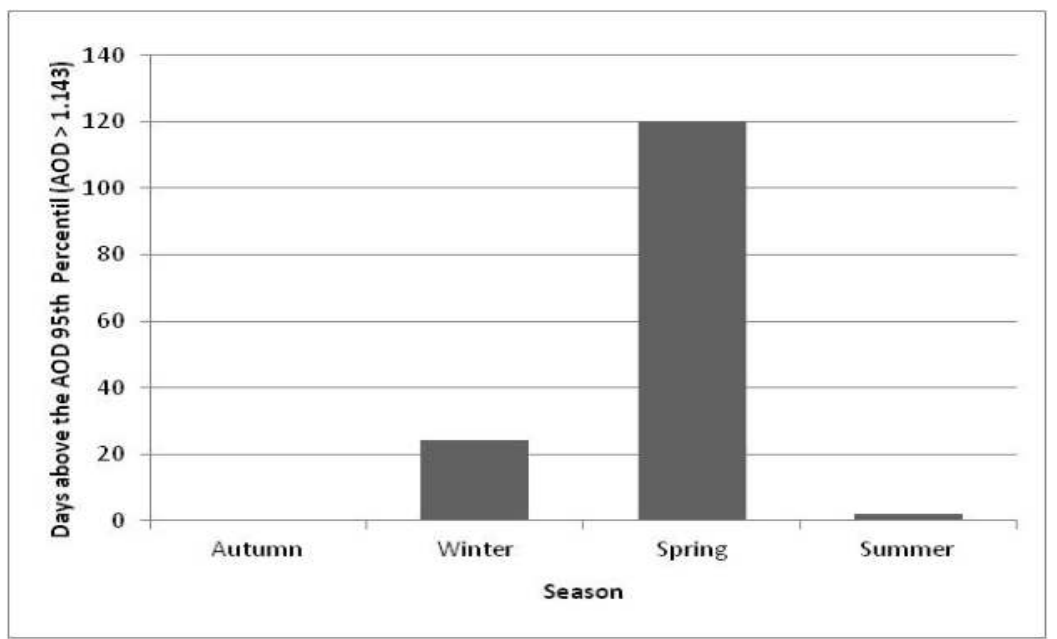

Figure 4. Days above the AOD 95 th Percentile (maximum AOD by MODIS $>1.143$ ) over southeast of Brazil

\section{Aerosol detection in the burning region}

As mentioned before, some regions in the Brazilian territory suffers from intense anthropogenic biomass burning activities, such as forest and sugarcane plantation fires, during the so-called dry season. High concentrations of biomass burning aerosol particles, produced mainly in the Amazon basin and the Brazilian Mid-Western region, can be detected due to these fire activities in the tropical forest, savanna and pasture [35]. In this context, data from AERONET sunphotometer, MODIS sensor and CALIPSO satellite were employed in order to detect possible sources of biomass burning aerosols and map its transportation from Mid-Western to the Southeastern region in Brazil.

Initially the image data measured by the MODIS sensor aboard the Terra satellite were used to identify possible signs of smoke from biomass burning. In the image retrieved on 21 August 2007, presented in Figure 5, it can be clearly seen the presence of a dense smoke layer in the region South and Southeast of Campo Grande (CG - Lat: 20²6'16" Long: $\left.54^{\circ} 32^{\prime} 16^{\prime \prime}\right)$. The trajectories generated using the HYSPLIT model indicate the transport of air masses from the Midwestern region of Brazil to the Southeast, where the MSP-Lidar system and the AERONET sunphotometer are installed. Figure 5 also shows that the CALIOP sensor aboard the CALIPSO satellite overpass the region near of Campo Grande during the nighttime of 21 August 2007, as can be seen by the descending trajectory (in the left of Figure 5). Furthermore, the sensor made measurements during daytime on the same day, however, in a region between the cities of Campo Grande and São Paulo, which will be helpful in the monitoring processes of the aerosol transport from the region of CG to MASP. 


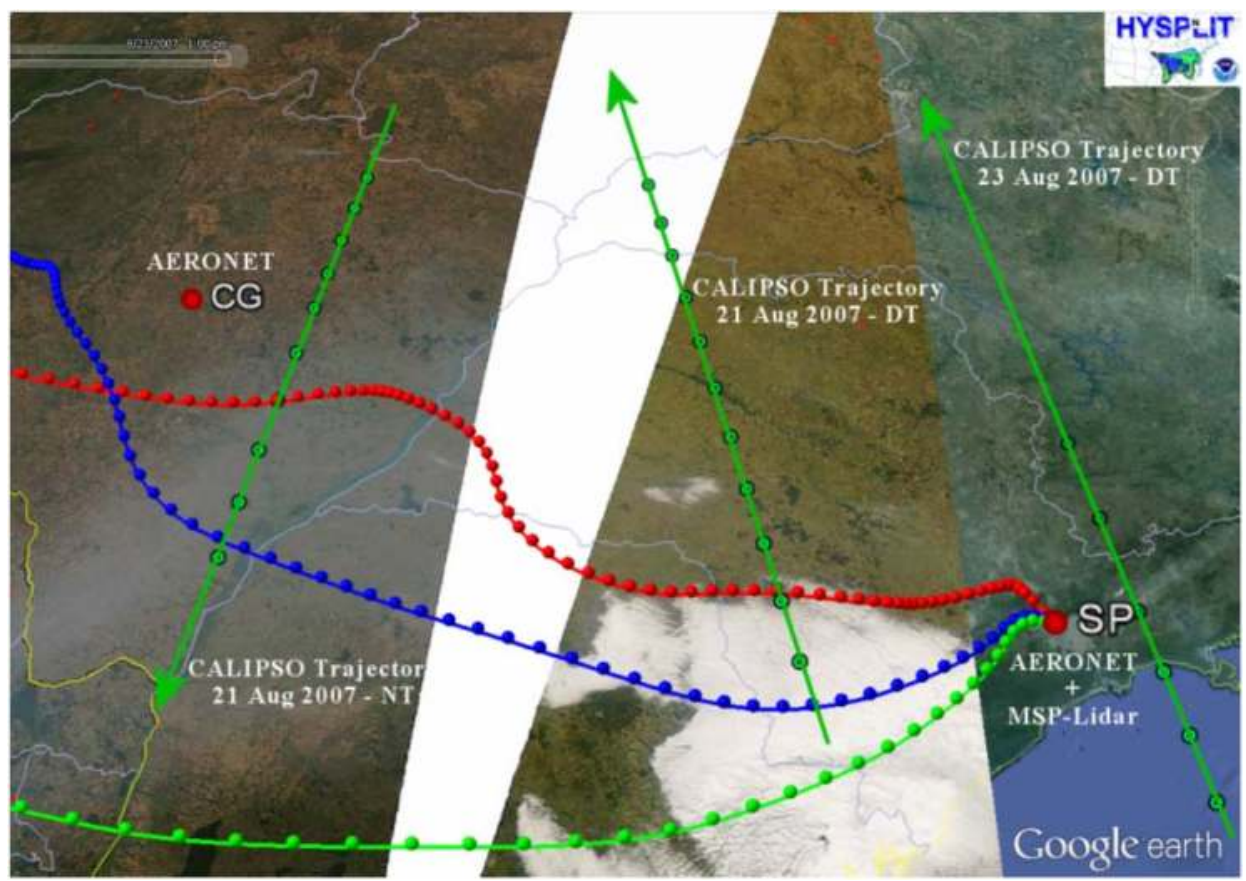

Figure 5. Image of the MODIS sensor aboard the Terra satellite showing a dense smoke layer in the South and Southwest region of Mato Grosso State (Campo Grande) on 21 August 2007. The green arrows show the nighttime (descending) and daytime (ascending) trajectories of the CALIPSO satellite for the same day. The trajectories generated by the HYSPLIT model show that aerosol masses were transported from the Midwestern region of Brazilian territory to the Southeastern region where the MSP-Lidar system and AERONET sunphotometer are installed.

After identifying the presence of a dense smoke layer through the MODIS image, some optical properties of the atmospheric aerosol retrieved by the AERONET sunphotometer installed in CG site were analyzed. The AOD and AE products can provide information about the absorption and extinction characteristics and the size distribution of the aerosol in the atmosphere. In general, high values of AOD are associated to high extinction (absorption) of radiation, and in the same reasoning, high values of $\mathrm{AE}$ are associated to the fine mode size distribution of aerosols. These two characteristics are considered a signature of biomass burning aerosol. Figure 6 shows the scatter plot of Ångström Exponent as a function of the Aerosol Optical Depth for the month of August 2007 and case previously selected at Campo Grande (points in red), the grey filled lines are the AOD and AE median values for all data and the dashed lines are the respective median standard deviation. The $\mathrm{AE}$ values below the horizontal line corresponding to the median, $\mathrm{AE}=1.46 \pm 0.09$, are an indication that most of the aerosol load is in the coarse mode size distribution. Those values above the median line belong to the fine mode size type of aerosols. The AE indicates a small sized particle distribution similar to those found in the presence of biomass burning aerosols as shown by [36]. Making the same interpretation to the AOD median vertical line, 
$\mathrm{AOD}=0.198 \pm 0.078$, the values in the left side of the AOD median corresponding to low extinction and absorption of radiation aerosol types, and the right side is related to the high extinction and absorption radiation types. The median values were assumed as a better statistical evaluator since it was found using a skewness test that the AOD vs. AE distribution is rather asymmetrical, and instead of the standard deviation it has been used the median standard deviation as the measure of the variability or dispersion of the data set, according to [02]. The scatterplot in Figure 6 was divided into four distinctive sectors, I, II, III and IV. Each of them represents different types and sizes of aerosol according to the AOD and AE values. This study should be focusing mainly on regions II and IV, which correspond to fine mode size distribution and high absorption and extinction aerosol types, and coarse mode and high absorption and extinction aerosol types, respectively. In sector II there is a strong indication of the predominance of biomass burning aerosols in the atmosphere as the large AE corresponds to small sized particles and the large AOD for a strong absorbing type of aerosols. The same reasoning can be applied to sector IV, although the values below the AE median values can be associated to particle growth during the long-range transport [37]. As can be seen in Figure 6, the most AOD and AE values of aerosol measured during 21 August 2007 (red points) are inside the region II, representing biomass burning aerosol types.

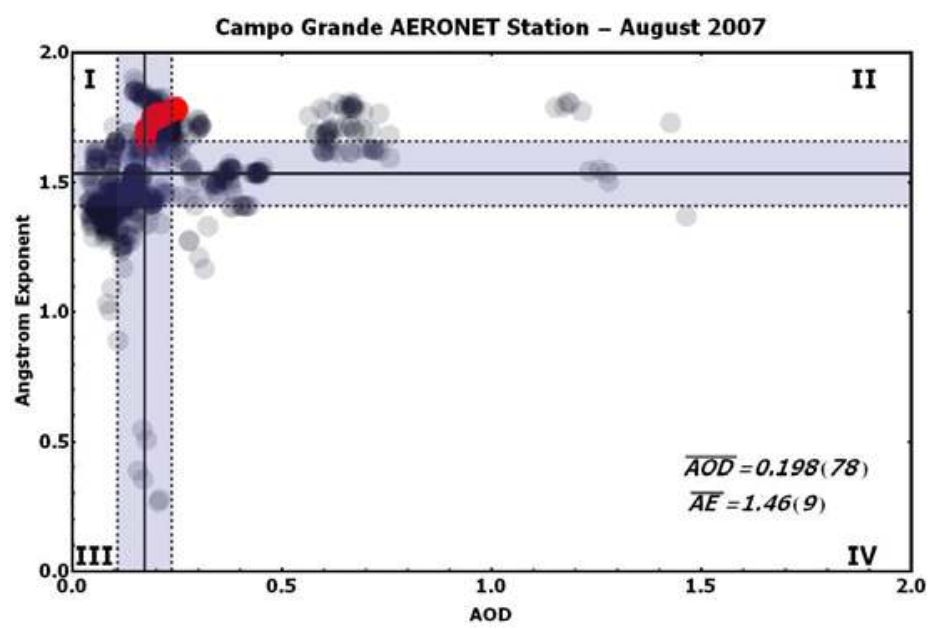

Figure 6. Scatterplot of the Ångström Exponent versus Aerosol Optical Depth at $532 \mathrm{~nm}$ for the case study selected (21 August 2007) and for the complete period of the August 2007. The four distinctive sectors represent different types and sizes of aerosol according to the AOD and AE values. The region II represents aerosols with biomass burning products characteristics, with high values of AOD and AE. The calculated median and median standard deviation values are $\mathrm{AOD}=0.198 \pm 0.078$ and $\mathrm{AE}=$ $1.46 \pm 0.09$, respectively.

On 21 August 2007, the CALIPSO satellite overpasses the region near the AERONET site in CG during the nighttime (descending trajectory), with the closest approach to the AERONET site of $126 \mathrm{~km}$ (horizontal distance) at 05:00 UTC approximately. During the 
daytime on the same day the satellite made measurements in an area between Campo Grande and São Paulo, as can be seen in Figure 5. The AOD and LR retrieved by the CALIOP sensor were obtained using the Level 2 Aerosol Layer products Version 3.0 for both trajectories during 21 August 2007. Figure 7 shows the AOD (left panel) and LR values (right panel) according to the latitude for the nighttime trajectory (21 Aug 2007 NT in figure 5).

In the left panel of figure 7 it can be observed the values of AOD retrieved by CALIOP sensor spanning from 0.65 to 0.30 . Such values are higher compared with those measured by the AERONET sunphotometer installed at CG site, represented by the red points in Figure 6 . The high values of AOD measured by CALIOP sensor are a strong indication that highly absorbent aerosols are present in the atmosphere; in addition, it is a strong indication that these particles are from biomass burning aerosols [38]. Such evidence is confirmed analyzing the Lidar Ratio values, which can indicate the most likely type of aerosol detected, as shown at the right panel of Figure 7. The CALIOP sensor signed LR values of $70 \mathrm{sr}$. According to [39, 40], the LR value of 70 sr corresponds to the aerosol type from biomass burning or continental polluted air. However, biomass burning aerosol types differ according to their detection altitude. Generally, such layers are detected above the PBL, localized approximately between 3 to $5 \mathrm{~km}$ and more [41,42]. In the case of the CALIOP nighttime measures on 21 August 2007 in the region of the CG's AERONET site, the detected layers correspondent to the AOD and LR values presented in Figure 7 were localized between 2.5 and $4 \mathrm{~km}$, which is Above the PBL, demonstrating that the detected layers are mostly loaded by biomass burning aerosols. The $532 \mathrm{~nm}$ Total Attenuated Backscatter profile presented in Figure 8 shows an intense backscatter signal from an aerosol layer at high altitude, localized above the PBL approximately between 2.5 and $4 \mathrm{~km}$, which is the biomass burning layer detected near the AERONET sunphotometer site at CG pointed by the dashed line in red. Such aerosol type is confirmed by the Vertical Feature Mask (VFM) product presented in Figure 9, which identifies the subtype of each aerosol in the atmosphere [43].
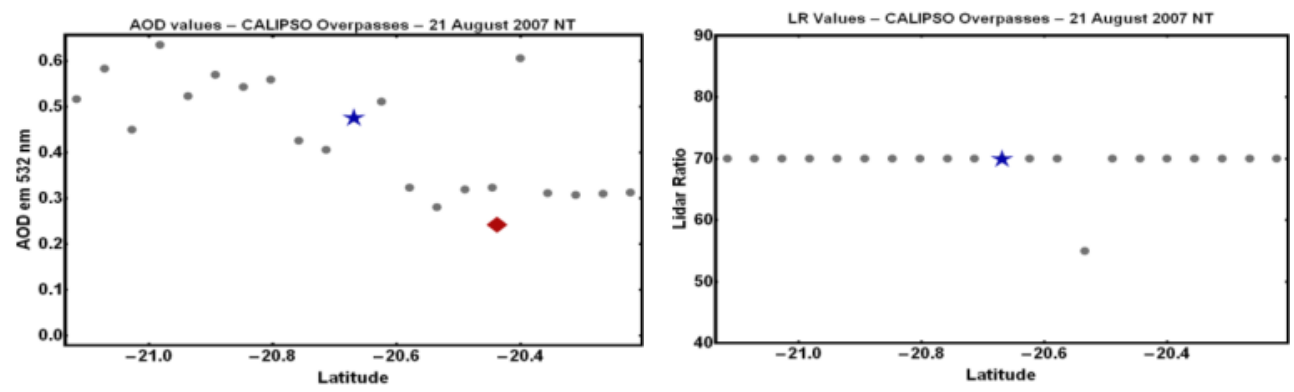

Figure 7. AOD and LR distribution as function of latitude (21 Aug 2007 - NT trajectory in figure 5) measured by the CALIOP sensor on 21 August 2007 during the nighttime. The star marks the point of the satellite closest approach to the AERONET site installed at CG. The red triangle represents the value of AOD measured by the AERONET sunphotometer during the closest approximation time. 




Figure 8. CALIOP $532 \mathrm{~nm}$ Total Attenuated Backscatter profile along with the orbit track in the graphic embedded in the upper left. The dashed line in red represents the closest approach to the region of Campo Grande on 21 August 2007 around 05:00 (UTC). It can be noticed an intense aerosol layer detached above the PBL, localized approximately between 2.5 and $4.0 \mathrm{~km}$ of altitude.

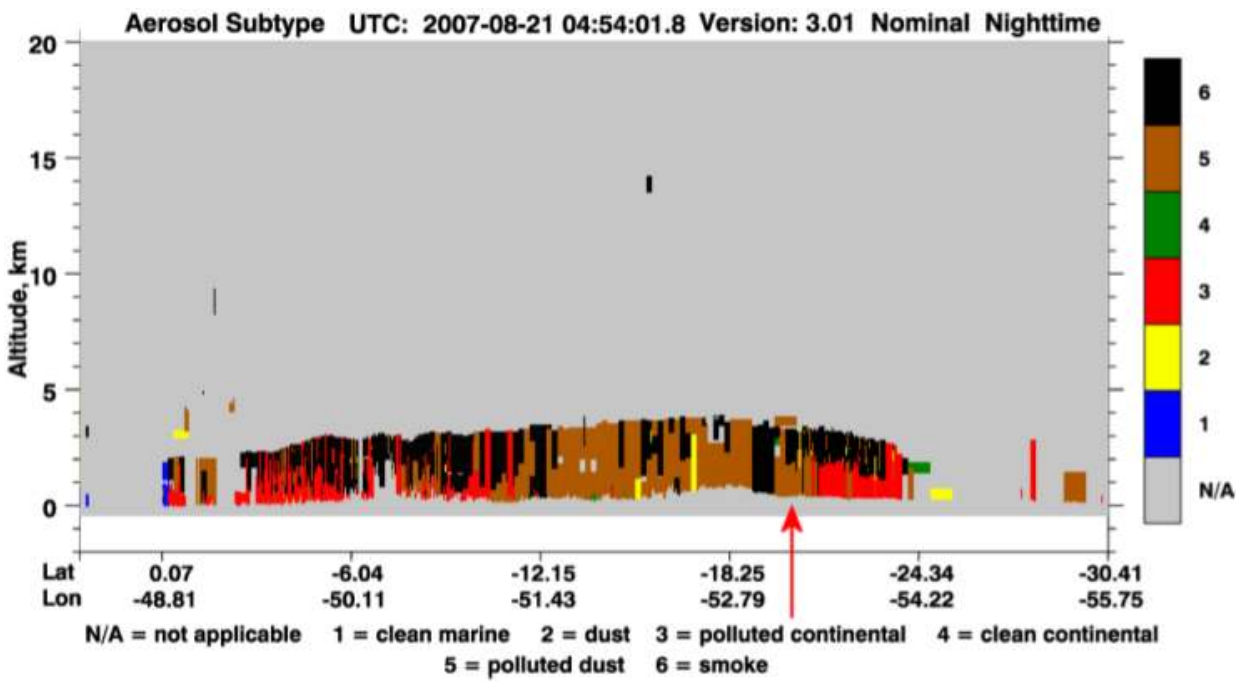

Figure 9. CALIOP Vertical Feature Mask of aerosol layers measured in the region of the CG's AERONET sunphotometer on 21 August 2007 around 05:00 (UTC). It can be seen an aerosol layer above the PBL localized approximately between 2.5 and $4.0 \mathrm{~km}$ altitude and classified as biomass burning aerosol type $(6=$ smoke). The layer immediately below, within the PBL, is classified as a mixture of dust and pollution $(5=$ polluted dust aerosol type $)$. 


\section{Transport and detection of biomass burning aerosols}

For the days when the presence of aerosols from biomass burning were detected by the sensors onboard CALIPSO and TERRA satellites, and also by the sunphotometer on CG site, air mass trajectories were generated using the HYSPLIT model, that is a complete system for computing simple trajectories to complex dispersion and deposition simulations using either puff or particle approaches [44]. The HYSPLIT trajectories are computed based on the Global Data Assimilation System (GDAS), an operational system from the National Weather Service of the National Centers for Environmental Prediction (NCEP) and it was used to investigate if the air mass parcels in the Midwestern have been dislocated towards the Southeastern region where the MSP-Lidar system is installed. The purpose to use this trajectory model is to constrain the direction of the air masses to improve the correlation between the optical properties (i.e., AOD and Lidar ratio) measured by two different instruments spatially separated, i.e., CALIOP sensor and ground-based AERONET sunphotometer and MSP-Lidar system. According to Figure 5, the HYSPLIT trajectories show that there were transportation of biomass burning aerosols generated in the Midwestern region of Brazil, i.e. Campo Grande region, to the Southeastern, where the MSP-Lidar system is installed, as well as an AERONET sunphotometer system. The same analysis presented in the previous section was performed to the daytime measurement made by the CALIOP sensor in its trajectory in the region between the cities of CG and SP (Figure 5), using the AOD and LR retrieved using the Level 2 Aerosol Layer products Version 3.0. Figure 10 shows the AOD (left panel) and LR values (right panel) as function of the latitude for the daytime trajectory (21 Aug 2007 - DT in Figure 5). It can be seen that in this region the CALIOP sensor obtained not so high AOD values, being around 0.10. The LR values varied around 40-55 sr, representing the dust aerosol type or a mixture of dust and pollution (polluted dust) $[39,40]$. In the left panel of Figure 10 low values of AOD can be observed, around 0.10. Such values are lower compared to those measured by the AERONET sunphotometer installed at CG site, represented by the red points.
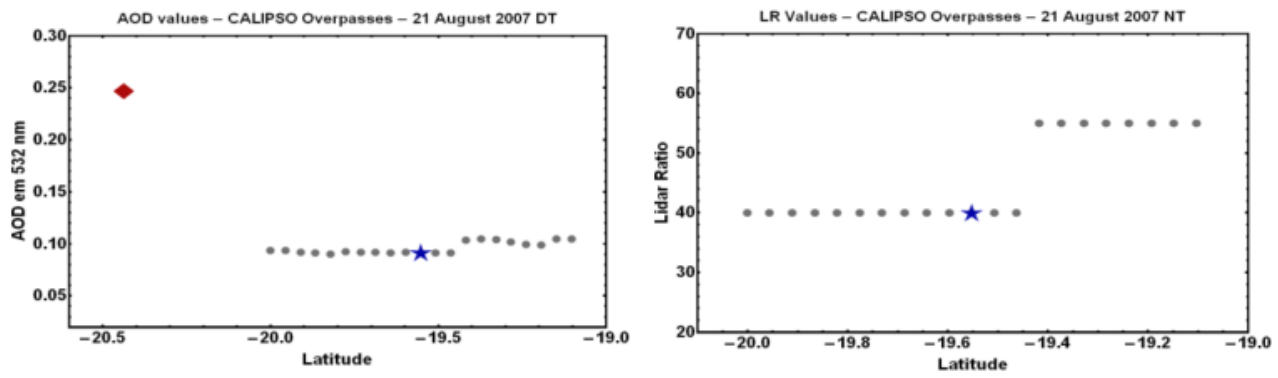

Figure 10. AOD and LR distribution as function of latitude (21 Aug 2007 - DT trajectory in figure 5) measured by the CALIOP sensor on 21 August 2007 during the daytime. The star marks the point of the satellite closest approach to the AERONET site installed at CG. The red triangle represents the value of AOD measured by the AERONET sunphotometer during the closest approach time. 
Two possible reasons can explain the detection of different values of AOD and LR from those values retrieved on the nighttime measurements (Figure 7). The first one is that the detected aerosols have their optical properties changed due to long-range transport, mixing with other aerosol types or absorbing moisture from the atmosphere, undergoing aging processes. The low value of the Lidar ratio (40 to $55 \mathrm{sr}$ ) also indicates the aging processes of the aerosols; such lower values may be linked to an increase of particle size by moisture absorption and/or a reduction of the light absorption capability of the particles [37]. However, the second reason can be the fact of the transported aerosol masses only reaches the region measured by the CALIOP sensor on 22 August 2007, a day after the CALIPSO satellite overpasses.

\section{Aerosol detection over the metropolitan region of São Paulo}

In order to track the biomass burning plume detected near the AERONET sunphotometer site in Campo Grande, backtrajectories were generated using the HYSPLIT model. Those backtrajectories show that the aerosol plumes were transported from the Midwestern region, near Campo Grande, to the Southeastern of the Brazilian territory, more precisely to the city of São Paulo, where there are two remote sensing equipments installed, the AERONET sunphotometer and an elastic backscatter $532 \mathrm{~nm}$ Lidar system these backtrajectories, presented in Figure 5 and Figure 11, it is possible to observe that aerosol air masses trajectories start at different altitude levels (3.5, 4.0 and $4.5 \mathrm{~km}$ AGL) on 21 August 2007 and move towards the Southeastern part of Brazil, reaching the MASP on 23 August 2007 at an altitude also around 3.5 and $4.5 \mathrm{~km}$. The altitudes of the starting trajectories in CG region are at the same range altitude of the aerosol layers detected by the CALIOP sensor signed as biomass burning according to Figure 8 .

On 23 August 2007, measurements carried out with the MSP-Lidar system, between 12:40 and 22:12 UTC, show the MASP atmosphere heavily loaded by aerosols, in addition, in Figure 12 the presence of a thin aerosol layer above the PBL can be seen from 3.5 to almost 5 $\mathrm{km}$ of altitude. Such vertical profile measured using MSP-Lidar system together with the backtrajectories from HYSPLIT model give a strong indication that this thin layer detached from the PBL is composed by biomass burning aerosols from the Midwestern region of Brazil.

Backscatter profile analyses were performed applying the Klett inversion method together with the AOD values retrieved by the AERONET sunphotometer. The $532 \mathrm{~nm}$ backscatter profile, presented in Figure 13, was calculated for the period between 17:00 to 18:00 (UTC), which corresponds to the CALIPSO closest approach to the MASP. The backscatter maximum for this measurement period was observed between 0.5 and around $2.0 \mathrm{~km}$ altitude range. This aerosol layer showed a quite stable maximum of $0.0033 \mathrm{~km}^{-1} \mathrm{sr}^{-1}$ during the period of measurements and represents the aerosol trapped in the PBL layer. The Lidar ratio in this period presents a constant value of $41 \mathrm{sr}$, calculated between 0.5 
and $5.0 \mathrm{~km}$ range altitude, which represent the dust aerosol type [45]. Such values of LR are not consistent with those values for biomass burning; however, it should be kept in mind that the Klett's inversion method only provide a constant LR value for the whole atmosphere column; in addition, the MASP is considered one of the most polluted cities in the world, having several different aerosol types loaded in its atmosphere, which can turn the retrieval of the LR value and the confidence of the aerosol type classification very difficult tasks. Furthermore, the HYSPLIT backtrajectories leads to a strong indication that the detached layer between 3.5 and $5 \mathrm{~km}$ is the biomass burning aerosol transported from the Midwestern region of Brazil. Backscatter profile analyses performed in posterior time period (around 20:00 UTC) presents LR values of $60 \mathrm{sr}$, consistent to the biomass burning aerosol type according to [45].

NOAA HYSPLIT MODEL

Backward trajectories ending at 1700 UTC 23 Aug 07

CDC1 Meteorological Data

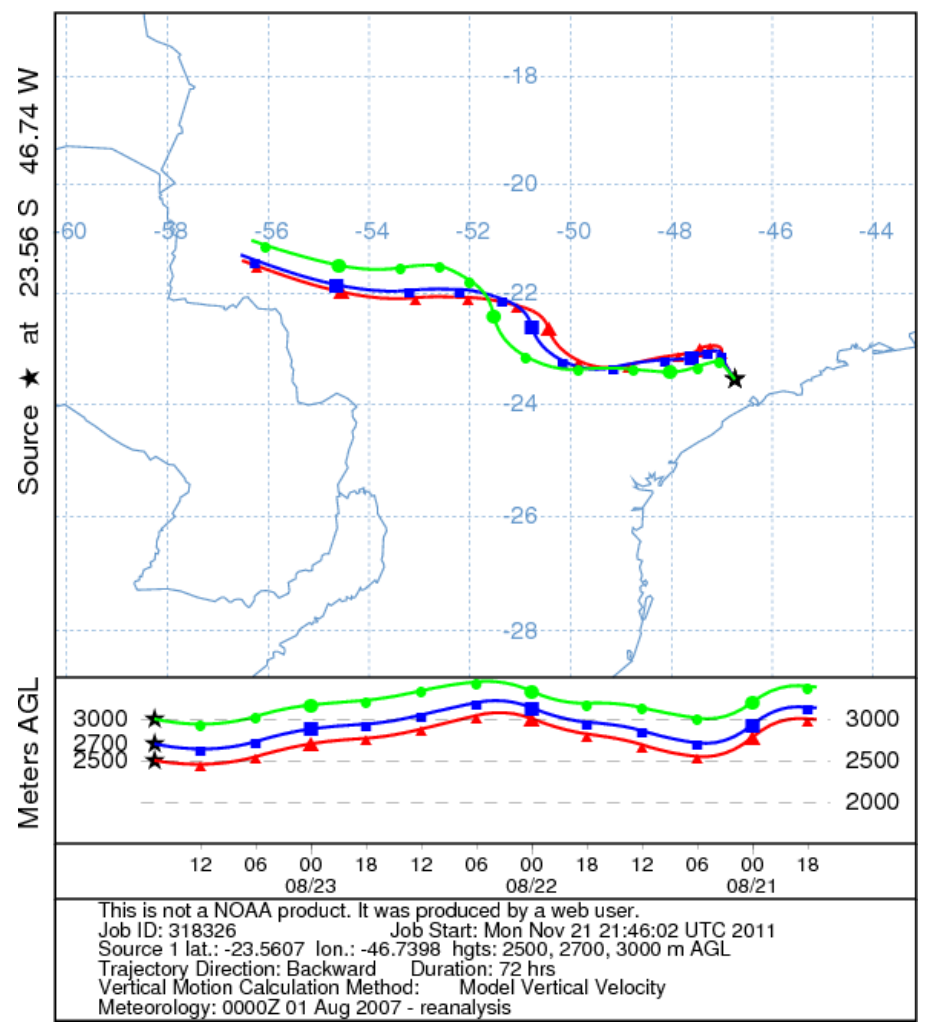

Figure 11. Air mass trajectories generated by the HYSPLIT model. Such trajectories identify the transport of aerosols from the Midwestern region of Brazilian territory on 21 August 2007 for the Southeast region of Brazil, reaching the MASP on 23 August 2007. 


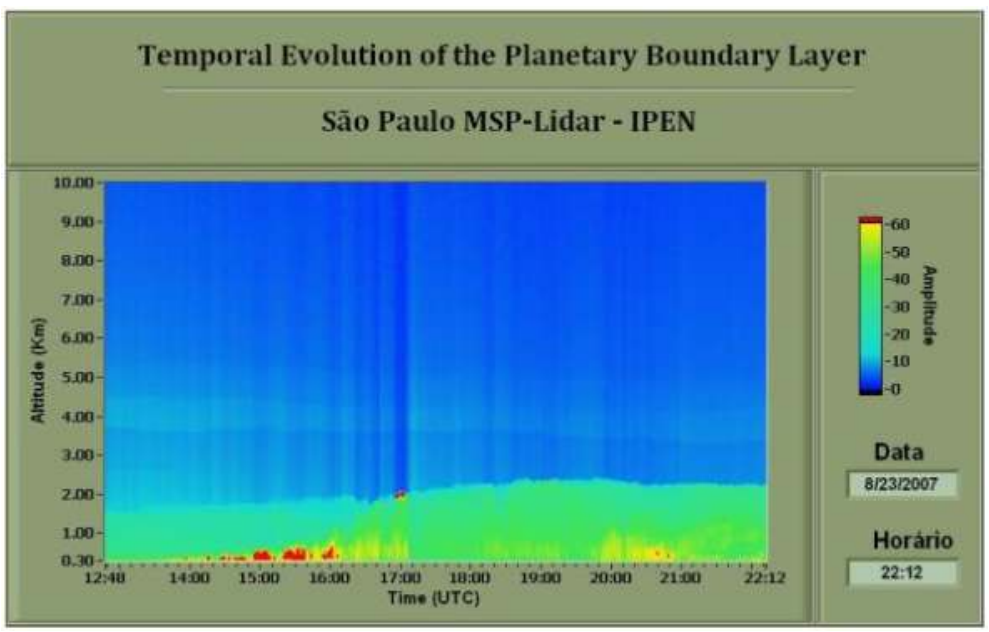

Figure 12. Range corrected backscatter profile at $532 \mathrm{~nm}$ for measurements carried out on 23 August 2007 by the MSP-Lidar system between 12:48 to 22:12 (UTC). It can be seen a thin layer of aerosol between 3.5 and $5 \mathrm{~km}$ transported from the Midwestern region of the Brazilian territory.



Figure 13. Backscatter coefficient profile at $532 \mathrm{~nm}$ measured on 23 August 2007 by the MSP-Lidar system between 17:00 to 18:00 (UTC).

On the same day the AERONET sunphotometer installed at MASP obtained AOD values spanning from 0.20 to 0.38 , indicating the detection of a high amount of absorbent aerosols loaded in the atmosphere of the MASP. Figure 14 shows the AOD and LR values obtained by the CALIOP sensor aboard the CALIPSO satellite on 23 August 2007, which overpasses the region close to MASP with closest approach of about $80 \mathrm{~km}$. The CALIOP AOD values for this case are spanning from 0.08 to 0.14 , which is quite low to the values retrieved by AERONET. Such difference between AOD retrieved by both instruments might have occurred due to the fact that the sunphotometer is installed within the MASP, which is 
considered one of the most polluted megacities of the world, with high quantity and variety of aerosols in its atmosphere. On the other hand, the trajectory of the CALIPSO satellite took place at about $80 \mathrm{~km}$ of horizontal distance to the east direction of the MASP, as can be checked in Figure 5. In this case, the CALIPSO satellite must have measured different aerosol layers with different optical properties from those measured by the AERONET sunphotometer. Furthermore, the values of LR are practically constant with values of $55 \mathrm{sr}$, representing aerosols of dust or polluted dust types. Taking into account the closest distance between CALIPSO trajectory and the MSP-Lidar system site, these CALIOP LR values can be considered in agreement with that retrieved by the MSP-Lidar system, which obtained values spanning from 33 to $66 \mathrm{sr}$ in the whole time period (Figure 12).


Figure 14. AOD and LR distribution as function of latitude (DT trajectory in Figure 5) measured by the CALIOP sensor on 23 August 2007 during the daytime. The star marks the point of the satellite closest approach to the AERONET site installed at MASP. The red triangle in the left panel represents the value of AOD measured by the AERONET sunphotometer during the closest approach time.

\section{Conclusions}

In this study, an extensive biomass burning event observed at two different sites in Brazilian territory and track the aerosol transportation from Midwestern to Southeastern region of Brazil have been described. The synergy of MODIS and CALIOP sensor, both aboard of satellites, the AERONET sunphotometer and the elastic backscatter Lidar system measurements allowed to estimate key optical characteristics of the aerosols observed during this event. These results are important for the radiative forcing study in the Brazilian territory and for the study of the effects of certain types of aerosol in the air quality of the megacities such as São Paulo, due to aerosols produced in the MASP as well as those transported from distant regions.

Spatial distribution of fires in the São Paulo State obtained by the NOAA-12 satellite indicates that the winter is the season with the highest number of fire outbreaks. In addition, during the harvest period, which occurs from May to November, the plantation areas are burnt a few hours before the manual cutting, resulting in large quantities of aerosols being emitted into the atmosphere. AOD measurements from MODIS sensor indicate high maximum values during spring and winter (Southeastern dry season). Average of the maximum AOD between 2003 and 2010 was $0.492 \pm 0.505$, indicating the high variability of the maximum AOD over this region. As in the Brazilian Southeastern region, the large 
occurrence of higher AOD levels during the dry season for the Midwestern region is basically due to the highest amount of biomass burning loaded in the atmosphere.

One day backtrajectories calculated for 21 August 2007 using the HYSPLIT model indicated that at 3.5, 4.0 and $4.5 \mathrm{~km}$ altitude air masses were advected from regions with intensive biomass burning activities in the Midwestern portion of the Brazilian territory. For the biomass burning episode under investigation in the Midwestern region on 21 August 2007, the AOD and LR at $532 \mathrm{~nm}$ was calculated using measurements from the CALIOP sensor and the AERONET sunphotometer installed at Campo Grande. The AOD retrieved by CALIOP sensor spanning from 0.30 to 0.65 and the LR was almost constant at $70 \mathrm{sr}$. The AERONET provides on the same day mean values of AOD and AE of 0.2 and 1.67, respectively, both values higher than the median in the August period (AOD $=0.198 \pm 0.078$ and $\mathrm{AE}=1.46 \pm 0.09)$. Such values correspond to fine mode size distribution and high absorption and extinction aerosol types, which is a strong indication of the predominance of biomass burning aerosols in the atmosphere. MODIS data image also provide a strong indication of biomass burning loaded in the atmosphere in the Midwestern region.

Daytime CALIPSO trajectory on 21 August 2007 together with the HYSPLIT backtrajectories provide evidences that air masses of biomass burning aerosol were transported towards the Southeastern region of Brazilian territory. However, AOD value of 0.10 and LR value of 40-55 sr indicate that those biomass burning aerosol layers have been undergoing an aging process, absorbing moisture from the atmosphere or even mixing with other aerosol types.

Air mass trajectories generated by the HYSPLIT model showed that these biomass burning aerosols were transported from the CG region towards the Metropolitan Area of São Paulo, reaching MASP on 23 August 2007 at an altitude range of 3.5 to $4.5 \mathrm{~km}$. The backscatter coefficient profile retrieved by the MSP-Lidar system showed an atmosphere heavily loaded of aerosol trapped within the PBL and also a distinguishable aerosol layer between 3.5 and 5 $\mathrm{km}$ of altitude. LR values retrieved by the MSP-Lidar, reaching maximum values of $66 \mathrm{sr}$, are in agreement with LR values of 55 sr signed by the CALIOP sensor. This LR value of 55 sr indicates the presence of polluted dust aerosol type instead of biomass burning type, though. However, it needs to be taken into account that the closest approach of the CALIPSO satellite was $80 \mathrm{~km}$ eastern of the MSP-Lidar site, which can lead to the fact that both instruments were not probing the same air mass parcels. Furthermore, the LR values retrieved from MSP-Lidar system in the whole period of time indicate the presence of several amount of aerosols present in the atmosphere of São Paulo, which can disguise the individual effect of the optical properties from biomass burning aerosols, which may have had their optical properties altered due to transport and aging processes [37].

This case study shows that the synergy and combination of analysis using several remote sensing instruments, whether passive or active, results in a better understanding of the aerosol optical properties in the atmosphere. Furthermore, these results show that aerosols produced in different regions can be transported by long-range distances. In this sense, megacities such as the Metropolitan Area of São Paulo, which have a large number of local aerosol sources is subject to the influence of aerosol pollution produced by remote sources. 


\title{
Author details
}

\author{
G. L. Mariano*
}

Federal University of Pelotas, UFPEL, Pelotas, Brasil

F. J. S. Lopes

São Paulo University, USP, São Paulo, Brasil

F. J. S. Lopes and E. Landulfo

Nuclear and Energy Research Institute, IPEN, São Paulo, Brasil

E. V. C. Mariano

National Institute for Space Research, INPE, São José dos Campos, Brasil

\section{Acknowledgement}

The authors wish to acknowledge all the CALIPSO team for data obtained from the NASA Langley Research Center Atmospheric. They also gratefully acknowledge the team of AERONET sunphotometer network, CPTEC/INPE for the active fires and the NOAA Air Resources Laboratory for the provision of the HYSPLIT transport and dispersion model and READY website used in this publication. The first author wishes to acknowledge the financial support of Fundacao para o Amparo da Pesquisa do Estado de Sao Paulo FAPESP under the project number 2011/14365-5. The secong author wish to acknowledge the Research Foundation of the State of Rio Grande do Sul and the post graduate program in Meteorology at the Federal University of Pelotas.

\section{References}

[1] Forster, P., Ramaswamy, V., Artaxo, P., et al. (2007): Changes in Atmospheric Constituents and in Radiative Forcing, in: Climate Change 2007: The Physical Science Basis. Contribution of Working Group I to the Fourth Assessment Report of the Intergovernmental Panel on Climate Change, edited by: Solomon, S., Qin, D., Manning, M., Chen, Z., Marquis, M., Averyt, K. B., Tignor, M., and Miller, H. L., Cambridge University Press, Cambridge, UK and New York, NY, USA.

[2] Landulfo, E., Lopes, F.J.S. (2009) Initial approach in biomass burning aerosol transport tracking with CALIPSO and MODIS satellites, sunphotometer and a backscatter Lidar system in Brazil. (2009) Proceedings of SPIE - The International Society for Optical Engineering 7479: 747905.

[3] Stephens, G.L., D.G. Vane, R.J. Boain, G.G. Mace, K. Sassen, Z. Wang, A.J. Illingworth, E.J. O'Connor, W.B. Rossow, S.L. Durden, S.D. Miller, R.T. Austin, A. Benedetti, C. Mitrescu, and CloudSat Science Team (2002) The CloudSat mission and the A-Train: A new dimension of space-based observations of clouds and precipitation. Bull. Amer. Meteorol. Soc. 83: 1771-1790.

\footnotetext{
${ }^{*}$ Corresponding Author
} 
[4] Barnes, W.L.; Tpagano, T.S.; Salomonson. V.V. (1998) Prelaunch characteristics of the Moderate Resolution Imaging Spectroradiometer (MODIS) on EOS-AM1. IEEE Trans. Geosci. Remote Sensing, 36: 1088-1100.

[5] Spiegel, M.R.; Stephens, L.J. (2009) Estatística. Porto Alegre: Bookman, 597p

[6] Coulson, K. L. (1975) Solar and terrestrial radiation: methods and measurements. New York: Academic Press. 479 p.

[7] Winker, D., W. H. Hunt, and M. J. McGill (2007), Initial performance assessment of CALIOP, Geophys. Res. Lett., 34, L19803, doi: 10.1029/2007GL030135.

[8] Winker, D. M., Vaughan, M.A., Omar, A., Hu, Y., Powell, K.A., Liu, Z., Hunt, W.Z., Young, S.A. (2009), Overview of the CALIPSO mission and CALIOP data processing algorithms, J. Atmos. Oceanic Technol., 26, 2310, doi:10.1175/2009JTECHA1231.1.

[9] Hunt, W. H., D. M. Winker, M. A. Vaughan, K. A. Powell, P. L. Lucker, and C. Weimer (2009), CALIPSO Lidar Description and Performance Assessment, J. Atmos. Oceanic Technol., 26, 1214, doi:10.1175/2009JTECHA1223.1

[10] Hostetler, C. A., Z. Liu, J. Reagan, M. A. Vaughan, D. M. Winker, M. Osborn, W. H. Hunt, K. A. Powell, and C. Trepte (2006), CALIOP Algorithm Theoretical Basis Document - Calibration and level 1 data products. Release 1.0, PC-SCI-201 Part 1, NASA Langley Research Center, Hampton, Virginia, USA, Available: http://www.calipso.larc.nasa.gov/resources/project documentation.php. Accessed 2012 May 07.

[11] Holben, B. N., Eck, T. F., Slutsker, I., Tanré, D., Buis, J. P., Setzer, A., Vermote, E., Reagan, J. A., Kaufman, Y. J., Nakajima, T., Lavenu, F., Jankowiak, I., and Smirnov, A. (1998) AERONET a federal instrument network and data archive for aerosol characterization, Remote Sensing of Environment 66: 1-16.

[12] Ångström, A. (1964) The parameters of atmospheric turbidity. Tellus, 16, 64-75.

[13] Junge, C. (1963) Air chemistry and radioactivity. New York: Academic Press Inc., 382 pages.

[14] Deepak, A., Gerber, H.E. (1983) Aerosols and their climate effects. Series Report 55, International Council of Scientific Unions and WMO, Switzerland.

[15] D'Almeida, G.A., P. Koepke, and E. P. Shettle (1991) Atmospheric aerosols, global climatology and radiative characteristics. Deepak Publ. 561p.

[16] Hamonou, E., Chazette, P., Balis, D., Dulac, F., Schneider, X., Galani, E., Ancellet, G., Papayannis, A. (1999), Characterization of the vertical structure of Saharan dust export to the Mediterranean basin. Journal of Geophysical Research. 104: 22257-22270.

[17] Ferrare, R.A., Schols, J.L., Eloranta, E.W. (1991). Lidar observations of banded convection during BLX83. Journal of Applied Meteorology. 3: 312-326.

[18] Mel, S.H., Spinhirne, J.D., Chou, S.H., Palm, S.P. (1985) Lidar observations of vertically organized convection in the planetary boundary layer over the ocean. Journal of Climate and Applied Meteorology. 24: 806-821.

[19] Crum, T.D., Stull, R.B., Eloranta, E. (1987) Coincident Lidar and aircraft observations of entrainment into thermals and mixed layer. Journal of Climate and Applied Meteorology. 26: 774-788. 
[20] Balis, D., Papayannis, A., Galani, E., Marenco, F., Santacesaria, V., Hamonou, E., Chazette, P., Ziomas, I., Zerefos, C. (2000) Tropospheric LIDAR aerosol measurements and sun photometric observations at Thessaloniki, Greece. Atmospheric Environment. 34: 925-932.

[21] Chourdakis, G., Papayannis, A., Porteneuve, J. (2002) Analysis of the receiver response for a non-coaxial Lidar system with fiber-optic output. Applied Optics. 41: 2715-2723.

[22] Papayannis, A., Chourdakis, G. (2002) The EOLE Project. A multi-wavelength laser remote sensing (Lidar) system for ozone and aerosol measurements in the troposphere and the lower stratosphere. Part ii: aerosol measurements over Athens, Greece. International Journal of Remote Sensing. 23: 179-196.

[23] Klett, J. D. (1981) Stable analytical inversion solution for processing Lidar returns. Appl. Opt. 20: 211-220.

[24] Klett, J. D. (1985) Lidar inversion with variable backscatter/extinction ratios, Appl. Opt. 24: $1638-1643$.

[25] Liou, K. N. (2002) An Introduction to Atmospheric Radiation, 2nd ed. Academic Press, California. 583p.

[26] Marenco, F., V. Santacesaria, A. F. Bais, D. Balis, A. di Sarra, A. Papayannis, and C. Zerefos (2002), Optical properties of tropospheric aerosols determined by Lidar and spectrophotometric measurements (Photochemical Activity and Solar Ultraviolet Radiation campaign), Appl. Optics, 36, 6875-6886, doi:10.1364/AO.36.006875.

[27] Bucholtz, A. (1995) Rayleigh-scattering calculations for the terrestrial atmosphere. Applied Optics. 34: 2765-2773, doi: 10.1364/AO.34.002765.

[28] Setzer, A. W.; Pereira, M. C. (1991) Amazonia biomass burnings in 1987 and an estimate of their tropospheric emissions. Ambio, 20: n. 1.

[29] Feltz, J. M., Prins, E.M., Setzer, A.W. (2001) A comparison of the GOES-8 ABBA and INPE AVHRR fire products for South America from 1995-2000. 11th conference on Satellite Meteorology and Oceanography, Bulletin of the American Meteorological Society 83: 1645-1648.

[30] Behera, D., Jindal, S.K., Malhotra, H.S. (1994) Ventilatory function in nonsmoking rural Indian women using different cooking fuels. Respiration 61: 89-92.

[31] Phonboon, K., Paisarn-Uchapong, O., Kanatharana, P., Agsorn, S. (1999) Smoke episodes emissions characterization and assessment of health risks related downwind air quality case study, Thailand. In: WHO Health Guidelines for Vegetation Fire Events. Geneva: World Health Organization: 334-358.

[32] Bruce, N., Perez-Padilla, R., Albalak, R. (2000) Indoor air pollution in developing countries: a major environmental and public health challenge. Bulletin WHO 78: 10781092.

[33] CETESB - Relatório de Qualidade do Ar no Estado de São Paulo (2009) Secretaria Do Meio Ambiente, Série Relatórios, São Paulo. Available: www.cetesb.sp.gov.br. Accessed: 2012 Feb 14

[34] Artaxo, P., Castanho, A.D.A. (1998). Aerosol concentrations and source apportionment in the urban area of São Paulo, Brazil. IAEA. International Atomic Energy Agency. TEC DOC series. 
[35] Freitas, S. R. , Longo, K. M., Dias, M. A. F. S., Dias, P. L. S., Chatfield, R., Prins, E., Artaxo, P., Grell, G. A., F. S. Recuero, (2005) Monitoring the transport of biomass burning emissions in South America. Environmental Fluid Mechanics. 5: 135-167.

[36] Kaskaoutis, D., Kambezidis, H., Hatzianastassiou, N., Kosmopoulos, P., Badarinath, K., (2007). Aerosol climatology: on the discrimination of aerosol types over four AERONET sites. Atmospheric Chemistry and Physics Discussions 7, 6357-6411.

[37] Müller, D., Ansmann, A., Mattis, I., Tesche, M., Wandinger, U., Althausen, D., Pisani, G., (2007). Aerosol-type-dependent lidar ratios observed with raman lidar. Journal of Geophysical Reasearch 112, D16202. doi:10.1029/2006JD00829.

[38] Amiridis, V., Balis, D.S., Giannakaki, E., Stohl, A., Kazadzis, S., Koukouli, M.E., Zanis, P. (2009) Optical characteristics of biomass burning aerosols over southeastern Europe determined from UV-Raman Lidar measurements. Atmospheric Chemistry and Physics. 9: 2431-2440. doi:10.5194/acp-9-2431-2009.

[39] Omar, A. H., J. G. Won, D. M. Winker, S. C. Yoon, O. Dubovik, M. P. McCormick (2005) Development of global aerosol models using cluster analysis of Aerosol Robotic Network (AERONET) measurements. Journal of Geophysical Research. 110: D10S14, doi:10.1029/2004JD004874.

[40] Omar, A. H., D. M. Winker, C. Kittaka, M. A. Vaughan, Z. Liu, Y. Hu, C. R. Trepte, R. R. Rogers, R. A. Ferrare, K.-P. Lee, R. E. Kuehn, C. A. Hostetler (2009) The CALIPSO automated aerosol classification and Lidar Ratio Selection Algorithm. Journal of Atmospheric and Oceanic Technology. 26: doi:10.1175/2009JTECHA1231.1.

[41] Freitas, S. R., K. M. Longo, J. Trentmann and D. Latham (2010)Technical Note: Sensitivity of 1-D smoke plume rise models to the inclusion of environmental wind drag. Atmospheric Chemistry and Physics. 10: 585-594. doi:10.5194/acp-10-585-2010.

[42] Liu, Z., A. H. Omar, Y. Hu, M. A. Vaughan, D. M. Winker (2006). CALIOP Algorithm Theoretical Basis Document - Scene Classification Algorithms. Release 1.0, PC-SCI-202 Part 3, 2005, NASA Langley Research Center, Hampton, Virginia, USA, Available: http://www.calipso.larc.nasa.gov/resources/project documentation.php. Accessed 2012 May 07.

[43] Vaughan, M. A., D. M. Winker, and K. A. Powell (2006) CALIOP Algorithm Theoretical Basis Document - Part 2: Feature detection and layer properties algorithms. Release 1.01, PC-SCI-202 Part 2, NASA Langley Research Center, Hampton, Virginia, USA, Available http://www.calipso.larc.nasa.gov/resources/project documentation.php]. Accessed 2012 May 07.

[44] Draxler, R., G. Hess (1998). Description of the Hysplit 4 modeling system, NOAA Tech. Memo. ERL ARL-224, NOAA Air Resources Laboratory, Silver Spring, MD, USA, Available: http://ready.arl.noaa.gov/HYSPLIT.php. Accessed 2012 May 07.

[45] Cattrall, C., Reagan, J., Thome, K., Dubovik, O. (2005). Variability of aerosol and spectral Lidar and backscatter and extinction ratios of key aerosol types derived from selected Aerosol Robotic Network locations. Journal of Geophysical Research. 110: D10S11. doi:10.1029/2004JD005124 